\title{
From work integrated learning to learning integrated work - A pedagogical model to develop praxis in nursing education
}

\author{
Bosse J onsson ${ }^{1}$, Maria Skyvell Nilsson ${ }^{2}$, Sandra Pennbrant ${ }^{2}$, Elisabeth Dahlborg Lyckhage ${ }^{2}$ \\ 1. Mälardalen University, Eskilstuna, Sweden. 2. University West, Trollhättan, Sweden.
}

Correspondence: Bosse J onsson. Address: Mälardalen University, Box 325, 63105 Eskilstuna, Sweden.

Email: bosse.jonsson@mdh.se

Received: J une 27, 2014

Accepted: August 28, $2014 \quad$ Online Published: September 15, 2014

DOI : 10.5430/jnep.v4n11p91

URL: http://dx.doi.org/10.5430/jnep.v4n11p91

\begin{abstract}
The move from student to nurse has been described as difficult for newly registered nurses. Newly registered nurses' feelings of lacking competence can reduce the opportunity to develop professional competence. Entering the nursing profession requires a high degree of adaptation. The difference between the professional competence conveyed during education and the competence demanded in working life is substantial and needs to be taken seriously. The aim of this paper is to propose a model for developing professional competence. The theoretical discussion starts with a model showing processes newly registered nurses must manage to achieve a sense of competence. These processes are highlighted by discussing how they relate to praxis in the Aristotelian tradition, situated learning and Work Integrated Learning (WIL). Learning Integrated Work (LIW) is a pedagogical approach aiming to integrate scientific knowledge with practical knowledge, and to provide an analytical perspective where students have the opportunity to develop metacognitive skills and praxis by learning in and by clinical practice experiences. One way to achieve this is to learn from the knowledge and skills used when performing practical work. The aims of WIL and LIW are to identify both practical knowledge generated by nurses in the course of their professional activities and theoretical knowledge generated in the academy, and to elaborate an understanding constituting the essence of both theoretical and practical knowledge. By integrating theoretical and practical vocational knowledge, one promotes professionalization, including the ability to perform the expected tasks and to have a critical and development-oriented attitude in daily work.
\end{abstract}

\section{Key words}

Learning integrated work, Nursing education, Praxis, Professionalization, Self-efficacy, Work integrated learning

\section{I ntroduction}

It is problematic for newly registered nurses to meet the demands made on them by both themselves and the healthcare organization in terms of developing their professional skills as nurses. A challenge for nurse educators is to prepare students for the professional demands facing them as newly registered nurses ${ }^{[1]}$. This calls for an approach integrating scientific knowledge and professional values with practical knowledge and clinical competence in order to develop praxis. In this paper, we will start with a model ${ }^{[1]}$, based on empirical data, highlighting the challenges facing newly registered nurses. 


\section{Aim and approach}

The aim of this paper is to propose a model for developing professional competence. The line of argument starts with a model identifying the processes newly registered nurses must go through and the circumstances surrounding them when becoming professional nurses. The model underlines the salient clinical experiences of newly registered nurses trying to develop professional skills in the context of clinical circumstances ${ }^{[1]}$.

\section{Background}

Nurses face difficulties in their professionalization. During their first year as registered nurses, they encounter working conditions and organizational circumstances that do not correspond to their professional identity as shaped during their nursing education ${ }^{[2]}$. They report feelings of not being able to understand and handle workplace demands, self-doubt, and fear of making mistakes ${ }^{[3,4]}$. Newly registered nurses describe fears of being "exposed” as clinically incompetent and of failing to provide safe care ${ }^{[5]}$. Studies also describe how entering the nursing profession requires a high degree of adaptation ${ }^{[2]}$. One may consider the difficulties experienced by newly registered nurses when developing their professional skills in light of the conflict between the professional role shaped during the education and the role demanded by the healthcare organization ${ }^{[6]}$.

Previous research shows how different pedagogical approaches in nursing education affect the move from being a student to becoming a nurse. In an evaluation of a nurse education program, Rystedt and Gustafson ${ }^{[7]}$ show that the relationship between theoretical knowledge and clinical practice is not described in a way enabling students to develop professional skills. Consequently, many students feel they are not prepared to be what Lave and Wenger ${ }^{[8]}$ call "legitimate participants" during clinical practice, resulting in a limited ability to learn. Newton, Billett, Jolly and Ockerby ${ }^{[9]}$ highlight that students question the relevance of what they learn in nursing school. Previous research on nurse education focuses on the "education-practice gap that is the ability of practice settings to adopt and reflect what was being taught in academic institutions. Now the tables are turned: there is a worry about the practice-education gap, as it becomes harder and harder for nurse education to keep pace with rapid change in a practice driven by research and new technologies” ${ }^{[10, \text { p. 4] }}$.

As mentioned above, this paper takes its starting point in a model (see Figure 1) focusing on the sub-processes newly registered nurses must go through when managing perceived obstacles in their efforts to integrate the knowledge acquired during their education with the organizational and clinical demands facing them as professional nurses. The model is based on data from two national cohorts of nurses within a population-based Longitudinal Analysis of Nursing Education (LANA) ${ }^{[11]}$. We analyzed statements from 330 newly registered nurses, provided in response to an open-ended questionnaire, describing factors affecting the experience and knowledge they bring from their education while developing professional skills in healthcare settings. Based on this analysis, we developed a model describing the complex interaction between the sub-processes and influencing factors facing new working nurses, as well as possible outcomes ${ }^{[1]}$.

The core process in the model is mastering the professional role. It includes three interrelated sub-processes: evaluating and re-evaluating educational experience, developing professional self-efficacy and developing clinical competence. The following factors influence the sub-processes: social values and norms; healthcare organization; and management of newly registered nurses, co-workers, patients and significant others, family and friends. These factors affect the professional development directly, indirectly or as mediating influences and lead to possible outcomes as newly registered nurses choose to remain in or leave the profession. Social values and norms are factors affecting the macro level. The healthcare organization is a factor influencing the meso level. Management of newly registered nurses, co-workers, patients and significant others and the influences of family and friends are factors affecting the micro level (see Figure 1).

In this paper Work Integrated Learning (WIL) and Learning Integrated Work (LIW) are considered as umbrella terms for a range of approaches and strategies seeking to integrate the theory of work practice with the practice of work within a 
purposefully designed curriculum ${ }^{[12]}$. WIL goes under different names. In English, it refers to both work integrated learning and cooperative learning, and another expression for it is Cooperative \& Work-Integrated Education (CWIE). WIL is both a way to organize vocational education and a strategy to give it specific content. WIL challenges the classic view of education, which sees scientific knowledge as a reliable and highly valued form of knowledge clearly separate from vocational skills. WIL requires the student to be situated in the workplace ${ }^{[12]}$. From this follows that the student is required to test theory by illuminating theory with experiences from practice.

Figure 1. A model illustrating the complex interaction between the subprocesses and influencing factors facing newly registered nurses ${ }^{[1]}$.

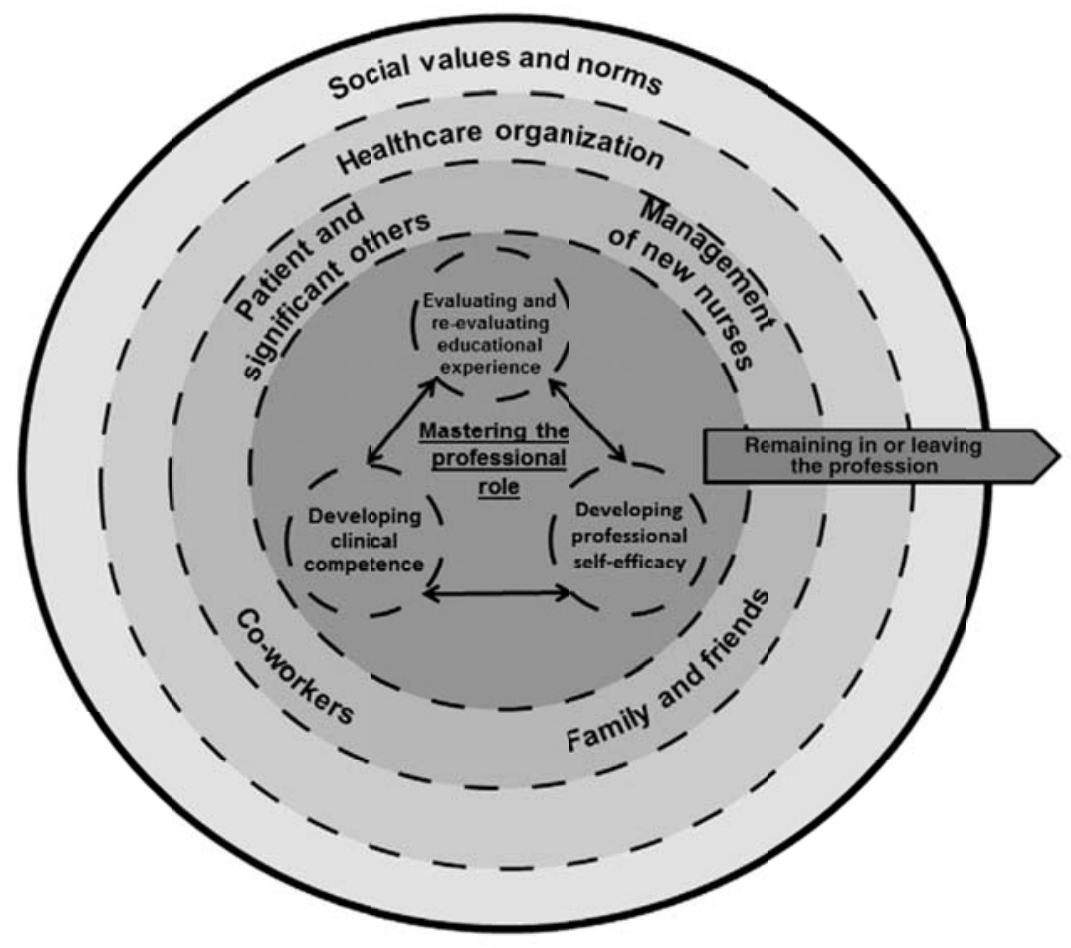

The purpose of LIW is to provide practical and working experience-based knowledge. Workplace learning focuses on developing competence and offers students an opportunity to develop the knowledge obtained through theoretical education. The education is also supposed to provide the students with advice and guidance for their learning process. This learning process encompasses both organizational, social and personal factors ${ }^{[13]}$ and produces understanding of what learning through work means. LIW is when the student has a job, perhaps as a nurse intern in a hospital, and integrates the theory learned from academia into their clinical practice in order to increase professional competence and preparedness.

Knowledge gained through formal learning in education is often expressed as scientific theories claiming general validity, whereas knowledge developed through informal learning serves as a foundation for being able to act in specific situations. In this paper, we define formal learning as learning taking place at a university or in an educational setting with the aim of generating learning, and we define informal learning as learning occurring in day-to-day interactions in settings where learning is not the aim. In general, as regards nursing education, it is taken for granted that formal learning at university is integrated with informal learning. From the perspective taken in this paper, informal learning is learning taking place in a caring activity in situations where specific tasks are to be performed ${ }^{[14]}$, even though the learners are not aware of the fact. Formal and informal learning must be integrated into more organized forms ${ }^{[15]}$. WIL requires reciprocity between formal and informal learning, and in this paper we regard it as an effort to systematize and conceptualize learning experiences in education and in other contexts. A challenge for nurse training is to elaborate a way to satisfy educational needs, workplace needs and, above all, students' needs ${ }^{[9]}$. 
Learning is situated, meaning it is embedded within an activity, context and culture. Informal learning is usually unintentional rather than deliberate. According to Lave and Wenger ${ }^{[8]}$, it is a case of "legitimate peripheral participation". A major challenge for nurse educators is to overcome this, and to provide students with tools to "bring theoretical and practical knowledge together to form a whole", i.e. praxis ${ }^{[16]}$. We understand praxis as an attempt to solve the dichotomy between theory and practice, idea and reality, thinking and doing. Our point of view is that one can move towards praxis, i.e. practical wisdom, by developing professional skills. The concept of praxis focuses on actions taking place when practice and theory confront each other.

We use classical epistemological concepts in this paper in order to clarify our reasoning. By using these concepts, we illustrate contemporary views on knowledge. The roots of praxis derive from Aristotle's ethics, distinguishing theory from practical activities. Aristotle separates theory from practical purpose, and regards it as an end in itself, as the highest activity ${ }^{[17]}$. Aristotle distinguishes between the ability to enunciate theory by scientific knowledge, i.e. episteme; the target action, i.e. techne; and the act as a target, i.e. phronesis or wisdom ${ }^{[18]}$. Aristotle also distinguishes between poesis and praxis, which both are action-oriented ${ }^{[19]}$. Poesis is action showing up as an expression of techne, i.e. making a product that is separate from the act itself; the act has no intrinsic value, the product is the aim of the act. For instance, the goal of injecting a patient is to transfer medicine into the patient's body; the transfer is the aim of giving the injection, injecting has no meaning in itself. Praxis, however, means that the act has meaning in itself; no observable result is required, and "the goal of praxis coincides with the performance of the act itself" ${ }^{[19, \text { p. 191] }}$. Praxis shows up as an observable expression of ethical knowledge, phronesis, i.e. practical wisdom that is about performing an act increasing a sense of well-being. This occurs when theory, techne or lived experience, is considered in order to reach an ability to perform an act that is good in itself. For example, spending time with a patient and letting him or her narrate something does not generate an observable product, but it is still valuable. Thus, the act of praxis is an outcome of reflected knowledge gained through formal learning in education or of informal learning obtained through professional activity.

Arendt ${ }^{[20]}$ and Freire ${ }^{[21]}$ emphasize an ontological dimension of praxis, meaning the human being has an innate ability to achieve autonomy and emancipation, which is also valid for nurses in their professional exercise. From an educational perspective, the overall aim in nurse education is to unite theoretical scientific knowledge and practical vocational knowledge towards an ability to perform and reflect upon professional skills and experiences. We consider such a union to be a first step towards what Aristotle ${ }^{[22]}$ conceptualizes as practical wisdom, a certain kind of knowledge in the form of praxis.

\section{Results}

\subsection{The significance of praxis in nursing education}

The model argues for the importance of evaluating and re-evaluating the sub-processes and influencing factors and challenges newly registered nurses must handle in order to develop praxis. In this section, we describe how praxis may be developed in relation to the sub-processes and influencing factors.

\subsection{Evaluating and re-evaluating educational knowledge}

The model argues for the importance of evaluating and re-evaluating educational experiences, i.e. to identify practical knowledge in relation to scientific knowledge in educational contexts. To grasp the meaning of theoretical understanding in clinical practice, theoretical knowledge must be useful in clinical practice. The clarification of the model indicates how insufficient theoretical understanding may lower the nurse's perceived ability to act as a new nurse ${ }^{[1]}$. We relate this process to Aristotle's view on the difference between episteme and techne. Epistemic knowledge is similar to scientific knowledge, which is to possess theoretical knowledge, whereas professionalized experiential knowledge has similarities with the concepts of techne and phronesis. From the perspective of the student, this means a focus on the technical- 
practical performance of the nursing duties. The constraints and possibilities of episteme and techne must be mutually recognized. According to Jonsson, "to learn episteme or to learn techne as they have been institutionally interpreted is to

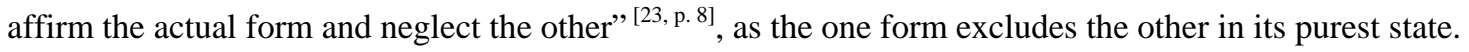

Praxis connects skills and knowledge in the nurse's professional role ${ }^{[24]}$. It is possible to understand praxis as something connecting abstract knowledge (to know and understand) to concrete applications (to do), i.e. a synthesis of theoretical knowledge and practical knowledge. It is also possible to understand praxis as a synthesis because praxis solves the dichotomy between theory and practice. A fruitful way for researchers to explain the dialectics between theory and practice is to enunciate theories based on observations of practice in reality. One achieves understanding in vocational education when one tests the theoretical knowledge in practical situations. One does not simply reword the theoretical knowledge; one evaluates and re-evaluates it in view of the experiences from the education.

We can illustrate our reasoning with the following examples: Despite having received formal education on how to give injections, nurses gradually find their own ways of giving injections in response to the problems they experience when dealing with patients in specific situations. In other words, the nurses develop their skills by gradually integrating episteme and techne. The same applies to the conduct of conversations with patients. In this case, it is rather a matter of integrating episteme and phronesis. These two examples illustrate how praxis can be developed in different ways in different situations. Our ambition is to develop praxis systematically in nursing education.

\subsection{Developing professional self-efficacy}

The model argues for the importance of developing professional self-efficacy, which emerges as both an individual process and a social process, i.e. the feeling of being competent and fitting in, as well as being accepted by others. Professional self-efficacy relates to personal factors such as self-confidence, feelings of practical competence and receiving support from co-workers and management.

Starting from praxis as an ontological concept, we can put into words what happens when professional skills develop. Arendt ${ }^{[19]}$ believes that human beings through praxis have a possibility to develop an ability to realize themselves, to become beings of praxis. Freire ${ }^{[21]}$ considers praxis as a means for bringing knowing and doing together as a dialectical whole through which we understand the entirety of a practice requiring both theoretical and practical knowledge. Awareness and transformation of oneself can be seen as the most fruitful outcomes of nursing within the emancipating paradigm and praxis is a way to overcome human alienation in working life ${ }^{[20,21]}$. Professional self-efficacy is dependent both on the newly registered nurses' own knowledge as well as on the support received from co-workers and management. Development of praxis requires close collaboration with the surrounding world in different environments and social practices, with the goal of gaining knowledge related to specific fields, in what Lave and Wenger ${ }^{[8]}$ call a community of praxis. The training emphasizes "the ideology of nursing", whereas the workplace emphasizes the professional skills ${ }^{[2]}$.

\subsection{Developing clinical competence}

The model describes how the development of clinical competence relates to the ability to understand and handle clinical problems and situations. The development of clinical competence relates to theoretical knowledge as well as to an understanding of the meaning and constraints of nursing practice. Benner et al. ${ }^{[10]}$ describe practice situations as undetermined, open-ended, and changing over time. Nurses must first determine the nature of the clinical situation, i.e. what is more or less significant in the situations in an ongoing process where interpretations of clinical situations continuously lead to a developed practical experience. Consequently, even the theoretical knowledge required to explain and understand a specific situation will change with increased experience.

Clinical competence becomes the ability to understand what must be done, why and in what way. Developing clinical competence requires integration of theoretical and practical knowledge, problem-solving and analytical skills, and is a 
process that starts during education and continues throughout working life ${ }^{[1]}$. Praxis can thus be seen as in-depth clinical competence with several different theories, knowledge, norms, values and attitudes that are considered and interpreted in relation to the healthcare organization's expectations and requirements.

\subsection{I nfluencing factors for praxis development}

In addition to the sub-processes, the model identifies a number of influencing conditions that are important for the nurses' professional development. The factors influencing newly registered nurses and their ability to develop praxis are social values and norms, the healthcare organization, management, co-workers and patients ${ }^{[1]}$. Co-workers are significant in developing professional skills. Newly registered nurses stress the importance of support and supervision for being able to handle clinical situations ${ }^{[1]}$, which is a prerequisite for continuous learning.

Despite having completed their clinical training and being equipped with humanistic values and theoretical knowledge based on science, harsh working conditions and organizational circumstances still hamper the nurses' professional development. Practice also involves unspoken implicit rules and sometimes lack of support and poor role models ${ }^{[25,26]}$. Today's healthcare organizations often involve time pressure, limiting the opportunity for newly registered nurses to develop their theoretical and practical knowledge into praxis ${ }^{[27]}$. The support they receive from their workplace mentors is insufficient ${ }^{[28]}$. In such organizations, it is difficult to obtain the desirable support highlighted in the model ${ }^{[1]}$.

\section{Discussion}

The model indicates that the development of praxis should start during the nurse education in order for newly registered nurses to master the sub-processes and influencing factors challenging them in working life. Pennbrant et al. ${ }^{[1]}$ show that newly registered nurses feel that their educators highlight normative aspects of nursing without providing them with the necessary tools for working in accordance with these values. Kirkevold ${ }^{[29]}$ stresses the importance of training for achieving a critical normative attitude. For the sake of their professionalization, it is important students understand the complex interplay between theoretical and practical knowledge early on in their education. It is therefore important that the education more clearly link theory to its practical application. To achieve this, we use Work Integrated Learning (WIL) and Learning Integrated Work (WIL) together as a pedagogical model focusing both on our goal for the academic nursing program and on learning that is more clearly linked to the daily nursing work. We believe this link can make it easier for students (and educators), in the course of the education, to understand how the theoretical normative content can be integrated with a practical and critical approach, and thus contribute to continuous development of praxis.

If the education covers both theoretical content and normative professional values, and problematizes them, students and newly registered nurses become stronger when confronted with clinical demands, and it becomes possible to strengthen theory with experiences of practice. The aim and outcome is ultimately to obtain a fusion of theory and practice into praxis.

One way to achieve this is to work based on WIL and LIW. By examining their clinical work using various theoretical tools relevant for the content of the course, students become capable of evaluating and re-evaluating the theoretical knowledge. To obtain an empirical foundation for the theoretical studies, students should provide examples of situations illustrating and clarifying the content of the normative theories, i.e. developing clinical competence. In other words, one can use the model as a pedagogical tool in seminars. To increase their critical ability, and bring theory and practice together as a whole, students should discuss and reflect their results together with their theoretical and practical educators as well as other students in study seminars.

We believe that it is easier for newly graduated nurses to develop their own role as nurses if they already in the course of their education have learned to link theory and practice, allowing them to develop their own professional self-efficacy and handle the various influencing factors. The seminars can serve as turning points in the learning, i.e. occasions when the 
notion of knowledge changes focus ${ }^{[30]}$. Turning points in learning occur when theoretical knowledge integrates with practical knowledge, or when clinical practice is understood on the basis of theory. To reflect is a way of integrating theory and clinical practice, thought and awareness, idea and reality ${ }^{[31]}$. If the planned course of action fails, the nurse students are forced to think and act differently.

Another question is whether the nurse's lack of ability to perform her work in the long run makes her professional role sustainable ${ }^{[32]}$. Falk Rafael ${ }^{[33]}$ distinguishes between three different types of nursing: ordered caring, assimilated caring, and empowered caring. Ordered caring is characterized by a lack of theoretical knowledge, assimilated caring is caring based on theoretical knowledge from medical science, and empowered caring integrates nursing sciences and healthcare ethics into nursing care. Falk Rafael ${ }^{[33]}$ links praxis to empowered caring, meaning the nurse conducts nursing that is in harmony with nursing values and knowledge from nursing science. This is praxis used in a way making it clear that there is a dialectical and mutual relationship between theoretical knowledge and practical knowledge. One sees theory and practice as being equally important. By combining the different forms of knowledge, one achieves a synthesis in the form of a new and greater form of knowledge, i.e. praxis. Development of praxis is a complex process, affected by the newly registered nurses' personal maturity, personal circumstances, the education and training they receive in their nurse education program, and by the organizational factors encountered in their new workplaces, including management practices and co-worker relations. The newly registered nurses are looking for different ways to develop professional skills and become more secure and autonomous in their role. It is through the process of sharing information and experiences with others that personal as well as a professional development are promoted ${ }^{[8]}$.

Benner ${ }^{[34]}$ moves the concept of praxis from the epistemological field and highlights the concept's ontology. According to Benner, nursing is praxis, reflective praxis, or reflective in practice. Newton and McKenna ${ }^{[35]}$ find that it is unrealistic to expect newly registered nurses to be able to develop knowledge and skills through critical reflection when their socialization, as well as the limits separating the training organization and the healthcare organization, hamper such reflection. It is important that theoretical knowledge be provided in different situations and contexts ${ }^{[36]}$. Previous research stresses that the development of praxis depends on individual factors such as self-efficacy and perceived competence, and on the working atmosphere in the healthcare organization, and it emphasizes the importance of an educational approach consistently striving to relate the theoretical and practical requirements with each other. Therefore, in order for newly registered nurses to develop professional skills, theoretical knowledge, and even nursing values, need to be combined with practical knowledge and personal experience. For a re-contextualization to take place, education and learning need to take place in relation to external circumstances, in order to further develop and implement improvements in nurse education ${ }^{[1]}$. Implementation of WIL in nursing education would be facilitated if the goals and aims of WIL were included in the internal institutional directions of universities and collaborating partners ${ }^{[12]}$. This would promote the creation of a critical mass where profession, education and healthcare staff can meet ${ }^{[37]}$.

A target for clinical practice should be to raise the students and educators' awareness of the nurse's development of praxis ${ }^{[17,24,38]}$. It is of importance "to affirm nursing practice as praxis and to acknowledge the epistemological diversity that sustains praxis” ${ }^{\text {[39, p. 133] }}$. By discussing and reviewing working conditions the students' experiences of work situations are illuminated as different ways of being, "being in praxis" or "being of praxis", as the contradictions between theory and clinical practice contribute to progress in terms of both modes of thought and modes of action. Clinical practice during education offers learning in work in future professional circumstances. Thus, it serves as a space and source for developing professionalization by trying and testing theory and values. In the course of examinations and seminars during practice, students should describe and discuss in what way the theory and values they brought from the classroom to caring activities influenced and deepened their proficiency. Conversely, seminars can be used to offer students an opportunity to discuss and improve the theoretical knowledge obtained prior to the practice. Such an approach will ensure that work integrated learning also means learning integrated work (see Figure 2). 
Figure 2. A model illustrating the complex interaction of sub-processes and influencing factors that students must deal with in order to create understanding and manifest praxis when moving from being a student to becoming a nurse.

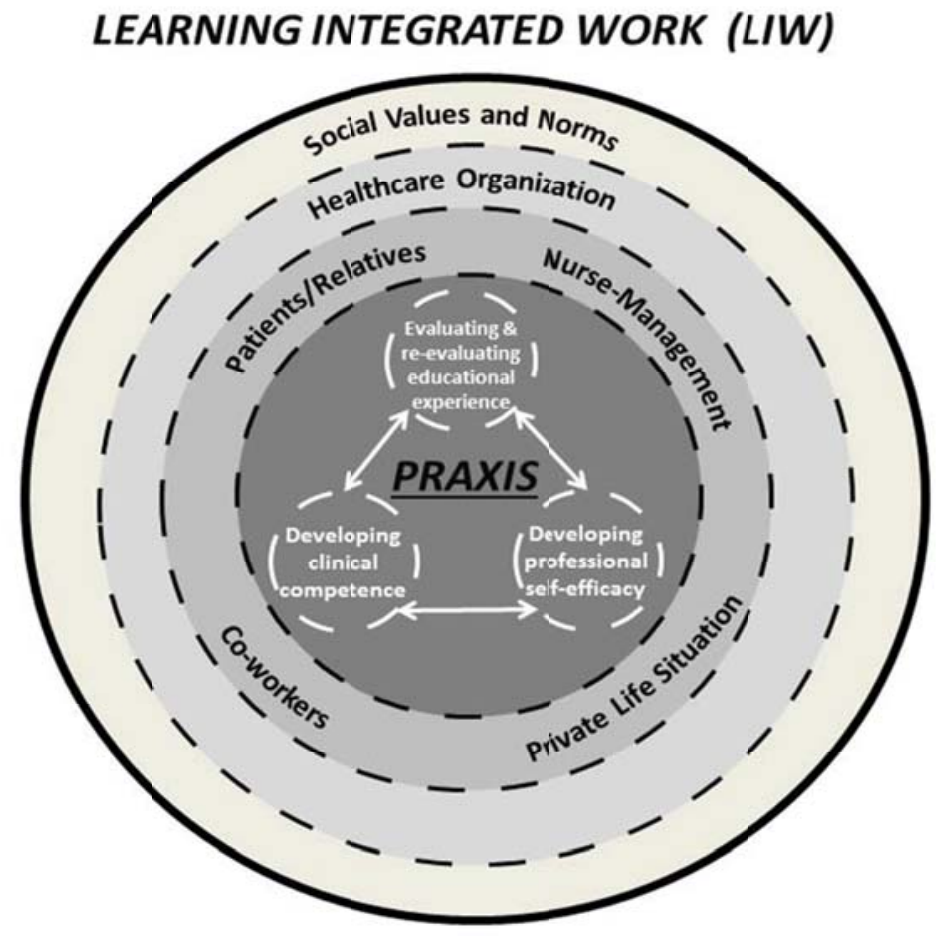

\section{Conclusion}

The purpose of Work Integrated Learning (WIL) and Learning Integrated Work (LIW) is to integrate scientific and theoretical knowledge with practical knowledge. One can use WIL and LIW as pedagogical models and analytical tools offering students the opportunity to develop their metacognitive skills and test their experiences, in order to create praxis. One way to achieve knowledge that is neither theoretical nor purely practical is to let nurses identify practical knowledge generated by nurses in the course of their professional activities, on the one hand, and theoretical knowledge generated in the academy, on the other hand.

By reviewing their working conditions, students can gain insights into how these conditions and their educational environment can bring about different ways of being, "being in praxis" or "being of praxis", as the contradictions between theory and clinical practice lead to progress in terms of both modes of thought and action.

The goal is to develop nursing education as a vocational program in a way that solves the dichotomy between the two kinds of knowledge. To, so to speak, develop praxis in clinical practice.

\section{Competing interests}

The authors declare that they have no competing interests.

\section{References}

[1] Pennbrant S, Skyvell Nilsson M, Öhlén J, Rudman A. Mastering the professional role as a newly graduated registered nurse. Nurse Education Today. 2013; 33(7): 739-45. PMid:23260623 http://dx.doi.org/10.1016/j.nedt.2012.11.021

[2] Bisholt BK. The professional socialization of recently graduated nurses - Experiences of an introduction program. Nurse Education Today. 2012; 32(3): 278-282. PMid:21546139 http://dx.doi.org/10.1016/j.nedt.2011.04.001

[3] Goodwin-Esola M, Deely M, Powell M. Progress meetings: facilitating role transition of the new graduate. Journal of Continuing Education in Nursing. 2009; 40(9): 411-415. PMid:19754028 http://dx.doi.org/10.3928/00220124-20090824-04 
[4] Higgins G, Spencer RL, Kane R. A systematic review of the experiences and perceptions of the newly qualified nurse in the United Kingdom. Nurse Education Today. 2010; 30(6): 499-508. PMid:19939524 http://dx.doi.org/10.1016/j.nedt.2009.10.017

[5] Duchscher JEB. Transition shock: the initial stage of role adaptation for newly graduated Registered Nurses. Journal of Advanced Nursing. 2009; 65(5): 1103-1113. PMid:19183235 http://dx.doi.org/10.1111/j.1365-2648.2008.04898.x

[6] Rung-Fen F, Yun-Fang T. Socialization of new graduate nurses to practicing nurses. Journal of Clinical Nursing. 2012 ; $21: 13-14$.

[7] Rystedt H, Gustafsson J. Authenticity and learning in a workplace based educational programme. In: Johnsson K, Lassbo G, Nehls E (Eds) (pp. 67-94). Inside the New University: Prerequisites for a Contemporary Knowledge Production. Bentham Science Publishers; 2013.

[8] Lave J, Wenger E. Situated Learning: Legitimate Peripheral Participation. Cambridge: Cambridge University Press; 1991. http://dx.doi.org/10.1017/CBO9780511815355

[9] Newton JM, Billett S, Jolly B, Cherene M, Ockerby CM. Lost in translation: Barriers to learning in health professional clinical education. Learning in Health and Social Care. 2009; 8, 4: 315-327. http://dx.doi.org/10.1111/j.1473-6861.2009.00229.x

[10] Benner P, Sutpen M, Leonars V, Day L. Educating Nurse - A Call for Radical Transformation. San Francisco, USA, Jossy-Bass; 2010.

[11] Rudman A, Gustavsson JP. Early-career burnout among new graduate nurses: a prospective observational study of intra-individual change trajectories. International Journal of Nursing Studies. 2011; 48: 292-306. PMid:20696427 http://dx.doi.org/10.1016/j.ijnurstu.2010.07.012

[12] Patrick CJ, Peach D, Pocknee C, Webb F, Fletcher M, Pretto G. The WIL [Work Integrated Learning] report: A national scoping study [Australian Learning and Teaching Council (ALTC) Final report]. 2008. Brisbane: Queensland University of Technology. Available online at: www.altc.edu.au and www.acen.edu.au.

[13] Lärande i arbete. Myndigheten för yrkeshögskolan. Dnr: YH 2012/3. 2012. Sweden.Available online at: www.myh.se/Documents/Publikationer/Myndighetens-syn-pa/myndighetens-syn-pa-lia.pdf

[14] Bjørk IT, Tøien M, Sørensen AL. Exploring informal leaning among hospital nurses. Journal of Workplace Learning. 2013; 25(7): 426-440. http://dx.doi.org/10.1108/JWL-01-2013-0003

[15] Tynjälä P, Slotte V, Nieminen J, Lonka K, Olkinuora E. From University to Working Life. Graduates’ Workplace Skills in Practice. In: Tynjälä P, Välimaa J, Boulton-Lewis G (Eds.) (pp. 73-88). Higher Education and Working Life - Collaborations, Confrontations and Challenges. Amsterdam: Elsevier; 2006.

[16] Dahlborg Lyckhage E, Pennbrant S. Work Integrated Learning - A didactic tool to develop praxis in nurse education. Advances in Nursing Science. 2014; 37(1): 61-69. PMid:24469089 http://dx.doi.org/10.1097/ANS.0000000000000018

[17] Wilson Nightingale AW. “Useless” Knowledge. Aristotle’s rethinking of Theoria. Spectacles of Truth in Classical Greek Philosophy (pp. 187-252). Cambridge: Cambridge University Press; 2004. http://dx.doi.org/10.1017/CBO9780511482564

[18] Liedman S. Marx and Engel’s Philosophical Writings. Stockholm, Sweden: Cavefors Forlag; 1978.

[19] Balaban O. Praxis and Poesies in Aristotle’s practical philosophy. The Journal of Value Inquiry. 1990; 24: 185-198. http://dx.doi.org/10.1007/BF00149432

[20] Arendt H. The Human Condition. Chicago, IL: The University of Chicago Press; 1958.

[21] Freire P. Pedagogy of the Oppressed. New York, NY: Continuum; 1970.

[22] Aristotle. Nicomachean Ethics. Translated and edited by Roger Crisp. Cambridge: Cambridge University Press; 2000. http://dx.doi.org/10.1017/CBO9780511802058

[23] Jonsson B. Work integrated learning as praxis. Paper presented at: 5th International Conference on Research Work and Learning (RWL5). 2007. Cape Town, South Africa. Peer reviewed.

[24] Connor MJ. The practical discourse in philosophy and nursing. An exploration of linkages and shifts in the evolution of praxis. Nursing Philosophy. 2004; 5: 54-66. PMid:15043698 http://dx.doi.org/10.1111/j.1466-769X.2004.00152.x

[25] Maben J, Latter S, MacLeod Clark J. The theory-practice gap. Impact of professional-bureau work conflict on newly-qualified nurses. Journal of Advanced Nursing. 2006; 55(4): 465-477. PMid:16866842 http://dx.doi.org/10.1111/j.1365-2648.2006.03939.x

[26] Standing M. Clinical decision-making skills on the developmental journey from student to Registered Nurse: a longitudinal inquiry. Journal of Advanced Nursing. 2007; 60(3): 257-269. PMid:17850295

[27] Kukulu K, Korukcu O, Ozdemir Y, Beczi A, Calik C. Self-confidence, gender and academic achievement of undergraduate nursing students, Journal of Psychiatric and Mental Health Nursing. 2013; 20(4): 330-335. PMid:22583626 http://dx.doi.org/10.1111/j.1365-2850.2012.01924.x

[28] Henderson A, Newton J. Commentary on Christiansen A, Bell A. Peer learning partnerships. Exploring the experience of pre-registration nursing students. Journal of Clinical Nursing. 2010; 19: 803-810, Journal of Clinical Nursing. 2010; 19 : $23-24$. http://dx.doi.org/10.1111/j.1365-2702.2010.03237.x 
[29] Kirkevold M. Sykepleievitenskap-epistemologiske overveielser. In: Östlinder S, Söderberg S, Öhlen J. Omvårdnad som akademiskt ämne. Rapport från en arbetande konferens. Stockholm: Svensk sjuksköterskeförening; 2009.

[30] Marton F, Booth S. Learning and Awareness. Mahwah, NJ: Erlbaum; 1997.

[31] Schön D. The reflective practitioner. How professionals think in action. Farnham: Ashgate Publishing; $1983 / 2011$.

[32] Maben J, Latter S, MacLeod Clark J. The sustainability of ideals, values and the nursing mandate: Evidence from a longitudinal qualitative study. Nursing Inquiry. 2007; 14(2): 99-113. PMid:17518822 http://dx.doi.org/10.1111/j.1440-1800.2007.00357.x

[33] Falk Rafael A. Power and Caring: A Dialectic in Nursing. Advances in Nursing Science. 1996; 19(1): 3-17. http://dx.doi.org/10.1097/00012272-199609000-00003

[34] Benner P. From novice to expert: Excellence and power in clinical nursing practice. Menlo Park, Calif., Addison-Wesley; 1984.

[35] Newton JM, McKenna LG. Uncovering knowing in practice during the graduate year. An exploratory study. Contemporary Nurse. 2009; 31(2): 153-162. http://dx.doi.org/10.5172/conu.673.31.2.153

[36] Säljö R. Föreställningar om lärande och tidsandan. In: Selander S (pp. 71-89). Kobran, nallen och majjen. Tradition och förnyelse i svensk skola och skolforskning. Stockholm: Myndigheten för skolutveckling; 2003.

[37] Evans K, Guile D, Harris J, Allan H. Putting knowledge to work: A new approach. Nurse Education Today. 2010 ; 30(3): $245-251$. PMid:19963307 http://dx.doi.org/10.1016/j.nedt.2009.10.014

[38] Kilpatrick K. Praxis and the role development of the acute care nurse practitioner. Nursing Inquiry. 2008; 15: 116-126. PMid:18476854 http://dx.doi.org/10.1111/j.1440-1800.2008.00404.x

[39] Tarlier D. Mediating the meaning of evidence through epistemological diversity. Nursing Inquiry. 2005; 12: 126-134. PMid:15892728 http://dx.doi.org/10.1111/j.1440-1800.2005.00262.x 